\title{
Effect of Active versus Expectant Nursing Management of Third Stage of Labor on Post-Partum Hemorrhage
}

\author{
Niven R. Basyouni \\ Assistant professor of Obstetrics and Gynecologic Nursing, Faculty of Nursing, Alexandria University/ Egypt
}

\begin{abstract}
Background: postpartum hemorrhage $(P P H)$ is the prime origin of maternal deaths. All laboring women are threatened by PPH and its toll. Prolonged 3rd stage of labor is one of the chief risk factors for PPH. To safe lives of women; proper nursing management of 3rd stage of labor is mandatory. Active or expectant nursing management of $3 \mathrm{rd}$ stage is the intervention of choice. Advantages and disadvantages of both techniques might be over estimated. Obstetric nurses must be prepared, competent and efficient to manage this situation at every delivery.

Objective: This study aimed to examine the effect of active versus expectant nursing management of the third stage of labor on post-partum hemorrhage.

Material and Methods: This quasi-experimental research was conducted in the labor and delivery unit of the Main Maternity University Hospital, Alexandria-Egypt. A convenient sample of 80 laboring women meeting the specified inclusion criteria were enrolled to the study. The women (80) were divided into two groups: active management and expectant management group. Each laboring woman in the previously mentioned groups was individually interviewed to collect data. Four days per week during a period of four months.

Results: This study found that a significant difference between the active and expectant management in the duration of the third stage of labor and the mean estimated blood loss during the $4^{\text {th }}$ stage of labor. While no statistically significant difference was found in the blood loss on labor ward as manifested by maternal vital signs and signs of shock. Likewise no significant relation was found in women's satisfaction with either active or expectant management of the $3^{\text {rd }}$ stage of labor.

Conclusions and recommendations: Active management of third stag of labor is preferable to expectant management in reducing post-partum hemorrhage (PPH). The implications of this study supporting the use of active management in a more widespread obstetric setting.
\end{abstract}

Keywords: Third stage of labor; Post partum hemorrhage (PPH); Active management of third stage of labor (AMTSL); Expectant management of third stage of labor.

\section{Introduction}

Life-threatening primary postpartum hemorrhage ( $\mathrm{PPH}$ ) occurs in around four percent of vaginal deliveries and two to eleven percent of all deliveries [1]. According to the WHO, it is a chief cause of maternal morbidity, and one of the pinnacle three origins of maternal mortality in both developed and developing countries [2]. PPH has conventionally been defined as loss of more than half liter of blood coming through the vagina within the first twenty four hours after birth [3]. Prevention of this life threading complication; includes diminishing anticipated risk factors and stimulating the uterus to contract soon after the fetus is born through the third stage of labor [1].

The third stage of labor is the time subsequent to delivery of the neonate until the full delivery of the placenta. Fairly scares research papers are dedicated to the third stage of labor parallel to that specified to the first and second stages. A prolonged third stage of labor (more than $30 \mathrm{~min}$ ) is associated with PPH [4]. To prevent this ring obstetric nurse ought to be proficient in both active management and expectant (physiological) management of the third stage of labor.

Active nursing management encompasses giving a prophylactic uterotonic (Oxytocin as doctor order), early clamping of the cord and prohibited cord traction [5]. Despite active management of third stage of labor (AMTSL) is recommended; facts on the application of the practice are inadequate. Statistics on its use in ten countries denoted utilization extending from null to the most of cases, without dissimilarity among developing and developed nations. A report from a main university teaching hospital in Egypt documented AMTSL in less than one-sixth of all births. While another in Istanbul, Turkey, accounted the use of Oxytocin in vast majority of child births during the third stage [6].

Expectant nursing management includes neither administration of a prophylactic uterotonic nor clamping and cutting the cord. But observations of placental separation's signs and encourages the use of gravity to help delivery of the placenta in an appropriate approach with woman participation [5]. This could be, through skin to skin contact and timely breast feeding. Also, reducing the length of the third stage of labor in a proactive 
approach through encouraging the woman to assume an upright position shortly after delivery may assist in diminishing blood loss with no need for oxytocics or cord traction [7]. This physiological management gives the woman the advantage of delayed cord clamping. Which is currently the optional performance identified to benefit the neonate, as it improvises iron storage till six months [8]. Accordingly, managing the third stage of labor is probably the most critical part of the labor process which determines the safety of the mother and the benefit for her baby.

\section{Significance of the study}

To support evidence based decision making; it is crucial now to consider the humanity of third-stage management. The obstetric nurse is able greatly to influence the outcome of the process of labor. She should given health education to the woman on both active and expectant nursing management of third stage of labor; advantages and disadvantages concerning the possible adverse effects of uterotonics. Also, she must be skilful in both maneuvers of managing the third stage of labor. Although benefits and risks of both methods must be recognized; data, especially on the local level, still lacks. Research studies are needed to shed light on the effect of active versus expectant nursing management of third stage of labor on PPH.

Aim: The aim of this quasi-experimental study was to determine the effect of active versus expectant nursing management of third stage of labor on post-partum hemorrhage.

\section{Material And Methods}

Setting: This study was conducted at the labor and delivery unit of the Main Maternity University Hospital, Alexandria-Egypt.

Subjects: The study Participants were selected by using the non-probability sampling technique where a convenient sample of 80 laboring women were recruited. All subjects should meet the specified inclusion criteria. These criteria include; primigravida, full-term (37 to 42 weeks of gestation), free from any medical or obstetric risk factors and/or conditions, have a single viable fetus in cephalic presentation and willing to participate in the study. The women (80) were assigned to one of two groups: a control (active management) and an experimental (expectant management) group. Each one was comprised of 40 women.

Tools: Two tools were used for data collection.

\section{Tool 1: Socio-demographic and clinical data structured interview schedule}

This tool was developed by the researcher to ensure that all study sample meeting the inclusion criteria. It was applied to women during the first stage of labor to collect the following data; socio-demographic characteristics including age and monthly income, history of recent pregnancy including antenatal follow up, history of current labor such as uterine contractions (duration, frequency, intensity and interval), rupture of membranes and presence of show as well as physical assessment including general assessment such as vital signs, and obstetrical examination such as fundal assessment.

\section{Tool II: Observational chick list}

This tool was developed by the researcher applied to women during the third and fourth stage of labor to collect the following data; blood loss on labor ward as shown by maternal vital signs and signs of shock, duration of third stage, estimated mean (SE) blood loss during 4th stage of labor, women's perceptions "Satisfied with third-stage nursing management", side-effects as Nausea, vomiting as well as or headache and manual removal of placenta.

\section{Methods}

Data collection procedure: Official approval from the directors of data collections settings was secured after explanation of the purpose of the study. Tools were developed by the researcher and reviewed for content validity by 9 faculty members specialized in the field of the study.

Ethical consideration: Ethical considerations: for each recruited subject were considered as; each woman was individually contracted and informed about the aim of the study in order to obtain her written consent. Each of those who agree to participate was assured about their confidentiality, privacy and right to withdraw at any time. Field work: A pilot study was carried out on five women to evaluate the applicability of tools and no modifications were done. Each laboring woman in the control and experimental group was individually interviewed to collect basic data using tool I. Four days per week were specified for data collection over a period of approximately four months from beginning of October 2015 to February 2016.

Each woman was assigned to one of the tow study groups as follows; the control group comprised 40 women; were receiving the active management of the third stage of labor by the researcher. This applied through; empty 
bladder, prophylactic uterotonic administration "Oxytocin as doctor order $10 \mathrm{IU}$ in $500 \mathrm{ml} 5 \%$ dextrose solution 16 drops/minute" approximately at the period of the neonatal birth, timely cord clamping within the first thirty seconds and cutting and controlled cord traction to accelerate delivery of the placenta as well as membranes [9]. The experimental group encompassed 40 women upon whom the expectant management of the third stage of labor was applied by the researcher. This involved waiting for signs of placental separation and allowing it to deliver spontaneously. This can be aiding by gravity through assuming upright positions and/or nipple stimulation.

The control group was started with and completed before starting the experimental group to avoid contamination of the sample. Incidence of post partum hemorrhage was evaluated for both experimental and control groups after the period of intervention and during the third and fourth stage of labor using tool II.

Blood loss on labor ward is evidenced by maternal vital signs and signs of shock. While Estimated mean (SE) blood loss during 4th stage of labor is evaluated through a standardized absorbent sanitary pad. When it is stained partly; the amount of blood loss is estimated to be $(30 \mathrm{ml})$. On the other hand when it is saturated to capacity; the blood loss is anticipated to be $(100 \mathrm{ml})$. For observation the pad was placed on a flat and nonabsorbent surface [10]. The effect of active versus expectant management of the third stage of labor on postpartum hemorrhage was determined by comparing the two groups after the intervention.

Data analysis: The collected data was fed, coded, edited and analyzed using SPSS version 20 for windows. Chi square (x2) test was significance at $\mathrm{p}$ value $<0.05$. Mean and standard deviation was considered for descriptive data. Independent $t$ test was used to examine whether there was any statistically significant difference between the control (active management) and the experimental (expectant management) group.

\section{Results}

Eighty laboring women, meeting the inclusion criteria were enrolled to the study sample. Out of which forty women were assigned to active management of third stage and the other forty experienced expectant management of third stage of labor.

In relation to their Socio-demographic and clinical data, no significant difference was found in between both groups. According to age, the difference is considered to be not statistically significant $(P=0.475)$. The average age of women in the active and expectant management groups was $24.7 \pm 2.75 \& 25.2 \pm 3.44$ years respectively. Also, no statistically significant difference was found in between the study groups in monthly income. Where $(\mathrm{P}=0.697)$ and the average monthly income was $865.0 \pm 114.21 \& 875.0 \pm 114.32$ in the active and expectant management groups respectively (Table 1).

Table (1) Distribution of the study sample according to their Socio-demographic and clinical data

\begin{tabular}{|c|c|c|c|}
\hline $\begin{array}{c}\text { Socio-demographic and } \\
\text { clinical data }\end{array}$ & $\begin{array}{c}\text { Control group } \\
\text { (Active management) } \\
(\mathrm{n}=40) \\
M(S D)\end{array}$ & $\begin{array}{c}\text { Experimental group } \\
\text { (Expectant management) } \\
(\mathrm{n}=40) \\
M(S D)\end{array}$ & P value \\
\hline Age (years) & $24.7 \pm 2.75$ & $25.2 \pm 3.44$ & $\mathrm{P}=0.475$ \\
\hline $\begin{array}{c}\text { Monthly income } \\
\text { (Egyptian Pound) }\end{array}$ & $865.0 \pm 114.21$ & $875.0 \pm 114.32$ & $\mathrm{P}=0.697$ \\
\hline
\end{tabular}

There wasn't any significant association observed in the blood loss on labor ward as evidenced by maternal vital signs and signs of shock. Where more than three quarters of active and expectant groups $82.5 \%$ \& $77.5 \%$ correspondingly had normal vital signs, with $(\mathrm{x} 2=0.313$ and $\mathrm{P}$ value equalizes 0.576$)$. None of the study sample suffered from signs of shock (Table 2).

Table (2) Distribution of the study sample according to blood loss on labor ward as shown by maternal vital

\begin{tabular}{|c|c|c|c|}
\hline Signs for blood loss on labor ward & $\begin{array}{c}\text { Control group } \\
\text { (Active management) } \\
(\mathrm{n}=40) \\
\text { No. }(\%)\end{array}$ & $\begin{array}{c}\text { Experimental group } \\
\text { (Expectant management) } \\
(\mathrm{n}=40)\end{array}$ & P value \\
\hline Maternal vital signs & $33(82.5 \%)$ & $31(77.5 \%)$ & $\mathrm{P}=0.576$ \\
\hline$\quad$ Normal & $7(17.5 \%)$ & $9(22.5 \%)$ & \\
\hline$\quad$ Abnormal & & & \\
\hline
\end{tabular}


Concerning the duration of third stage of labor; the difference was statistically significant between the two groups (The $\mathrm{x} 2$ is 55.503 and the p-value is < 0.001). As around two thirds $(67.5 \%)$ of the active management group had third stage ranging from five to less than ten minutes. While most of the expectant group had duration of third stage more than ten minutes. Per say $97.5 \%$ of expectant management group had third stage ranging from ten to twenty minutes or more the twenty minutes two on some (table 3 ).

Table 3: Distribution of the study sample according to duration of third stage

\begin{tabular}{|c|c|c|c|}
\hline $\begin{array}{l}\text { Duration of third stage } \\
\text { (In minutes) }\end{array}$ & $\begin{array}{c}\text { Control group } \\
\text { (Active management) } \\
(\mathrm{n}=40) \\
\text { No. }(\%)\end{array}$ & $\begin{array}{c}\text { Experimental group } \\
\text { (Expectant management) } \\
(\mathrm{n}=40) \\
\text { NO. }(\%)\end{array}$ & $P$ value \\
\hline$<5$ & $2(5.0 \%)$ & $0(0.0 \%)$ & \multirow{4}{*}{$* \mathrm{P}<0.001$} \\
\hline $5 \geq<10$ & $27(67.5 \%)$ & $1(2.5 \%)$ & \\
\hline $10 \geq<20$ & $4(10.0 \%)$ & $21(52.5 \%)$ & \\
\hline$\geq 20$ & $7(17.5 \%)$ & $18(45.0 \%)$ & \\
\hline
\end{tabular}

*Statistical significant

Similarly the difference was statistically significant between the active and expectant management groups in relation to estimated mean (SE) blood loss during 4th stage of labor. Where majority of women had blood loss less than $100 \mathrm{ml}$ in the active group, in expectant group most of the blood loss was between 100-200 $\mathrm{ml}$. Mean blood loss in active management group was $82.5 \pm 23.73 \mathrm{ml}$ and expectant group was $156.4 \pm 67.47 \mathrm{ml}$ $(\mathrm{t}=6.535 \& \mathrm{P}<0.001)($ table 4$)$.

Table 4: Distribution of the study sample according to estimated M (SE) blood loss during $4^{\text {th }}$ stage of labor

\begin{tabular}{|c|c|c|l|}
\hline $\begin{array}{c}\text { Blood loss during 4th stage of } \\
\text { labor } \\
(\text { In ML.) }\end{array}$ & $\begin{array}{c}\text { Control group } \\
\text { (Active management) } \\
(\mathrm{n}=40) \\
M(S D)\end{array}$ & $\begin{array}{c}\text { Experimental group } \\
\text { (Expectant management) } \\
(\mathrm{n}=40) \\
M(S D)\end{array}$ & P value \\
\hline$\quad \geq 100 \geq 200$ & $82.5 \pm 23.73$ & $156.4 \pm 67.47$ & $* \mathrm{P}<0.001$ \\
\hline
\end{tabular}

*Statistical significant

Regarding satisfaction with third-stage nursing management; no significant relation was found between the two study groups $(\mathrm{x} 2=0.552 \& \mathrm{P}=0.759)$. A sizable proportion of both groups said that they were satisfied with 3rd stage nursing management (70.0\% of active group compared to $62.5 \%$ of expectant group) (table 5).

Table 5: Distribution of the study sample according to Women's perceptions "Satisfied with third-stage nursing management"

\begin{tabular}{|c|c|c|c|}
\hline Women's perceptions & $\begin{array}{c}\text { Control group } \\
\text { (Active management) } \\
(\mathrm{n}=40) \\
\text { No. }(\%) \\
\end{array}$ & $\begin{array}{c}\text { Experimental group } \\
\text { (Expectant management) } \\
(\mathrm{n}=40) \\
\text { No. }(\%) \\
\end{array}$ & $P$ value \\
\hline $\begin{array}{ll}\text { Satisfied } & \\
\bullet & \text { Yes } \\
\bullet & \text { Uncertain } \\
\bullet & \text { No } \\
\end{array}$ & $\begin{array}{c}28(70.0 \%) \\
10(25.0 \%) \\
2(5.0 \%)\end{array}$ & $\begin{array}{c}25(62.5 \%) \\
12(30.0 \%) \\
3(7.5 \%)\end{array}$ & $P=0.759$ \\
\hline
\end{tabular}

\section{Discussion}

According to Kramer 2013; the incidence of sever life threatening PPH is two folded over ten years and no explanation can be provided [11]. The current research was done to compare active versus expectant management of third stage of labor, which can help obstetric nurses to avoid this preventable complication.

This study found that a significant difference between the active and expectant management in the duration of the third stage of labor and the mean estimated blood loss during the 4th stage of labor. While no statistically significant difference was found in the blood loss on labor ward as manifested by maternal vital signs and signs of shock. Likewise no significant relation was found in women's satisfaction with either active or expectant management of the 3rd stage of labor. None of the study sample complained of nausea, vomiting and or headache. Too manual removal of placenta wasn't applied for any of the study sample.

The International Federation of Gynaecology and Obstetrics (FIGO) encourages active management of the third stage of labor (AMTSL) in all laboring women so as to decrease the rate of postpartum hemorrhage (12). Two research papers the difference between them is more than ten years agreed with the current study result; Karim et al 2015 and Nothnagle \& Taylor 2003 [13, 14]. Karim et al 2015 in their research who 
demonstrated that AMTSL was superior on the expectant management with statistically significant lessen in the blood loss and shorter duration of 3rd stage of labor. Also according to Nothnagle \& Taylor 2003 active management was associated with a reduction in the maternal blood loss, less women with postpartum hemorrhage, and a lower occurrence of a prolonged third stage of labor. Correspondingly many studies have also illustrated the effect of AMTSL in the prevention of PPH [15-17].

Further more, Nothnagle stated in his research that; participants suffered from nausea and vomiting as well as elevated blood pressure as a disadvantage of ergometrine. This was not evident among women of present study sample [14]. Because the current study subjects used Oxytocin (as doctor order) which seems to be the medication of choice to avoid the side effects associated with ergometrine [18]. This fact is supported by Salvatore, et al. [19] as they said that prophylactic Oxytocin is the primary choice for PPH prevention. Ergot alkaloids, syntometrine, and prostaglandins are second-line uterotonic substances. Misoprostol is not efficient as oxytocin but it may be used when the latter is not accessible. Moreover '"Women who choose a less interventional maneuver in managing the third stage of labor can be reassured that when a uterotonic drug (Oxytocin) is used, schedule use of controlled cord traction can be omitted from the "active management" procedure without enhanced risk of severe PPH" Gill Gyte, said [20]. Which give the research a question about the effectiveness of each single component of the active management of the $3^{\text {rd }}$. stage of labor in the reduction of postpartum hemorrhage.

On the other hand, blood loss in the labor ward during the 3rd stage of labor hasn't differed significantly among study groups. This result can be interpreted that all cases were low risk of postpartum hemorrhage. Begley, et al. [5] congruent with the present study finding, since he mentioned "In a group of women at low risk of sever hemorrhage, there were similar findings, as there was no significant differentiation recognized between active and expectant management groups for incidence of severe hemorrhage during the third stage of labor". Also, many researches supported this finding as active management does not decrease blood loss during 3rd stage of labor when weighed against physiological or expectant management [21, 22].

Finally, AMTSL did not affect women's satisfaction with 3rd stage nursing management in this study. Sadler LC et al in their trial resulted that satisfaction with labor care was high and did not differ significantly by active management group [23]. Generally, this result can be contributed to the fact that women satisfaction with child birth experience is associated to factors such as individual expectations, the amount of support she receives, the quality of the nurse-patient relationship, and her participation in decision-making; rather than the maneuver of placental delivery [24].

\section{Conclusions}

Active nursing management of third stag of labor is preferable to expectant nursing management in reducing PPH. Active management gives significant results in reduction of mean blood loss during 4th stage as well as shorter duration of 3rd stage of labor.

\section{Recommendations}

Active nursing management of third stage of labor must be practiced in a more widespread obstetric setting. The researcher recommends further studies on the different elements of AMTSL to estimate their individual effectiveness.

\section{References}

[1]. Edhi MM, Aslam HM, Naqvi Z, Hashmi H. Postpartum hemorrhage: Causes and management. BMC Research Notes 2013;6:236

[2]. WHO. Maternal mortality Fact sheet N³48. Geneva: World Health Organization; 2015.

[3]. Weeks, A. "The prevention and treatment of postpartum hemorrhage: what do we know, and where do we go to next?" BJOG. 2015;122 (2): 202-10.

[4]. Frolova AI, Stout MJ, Tuuli MG, López JD, Macones GA, Cahill AG. Duration of the Third Stage of Labor and Risk of Postpartum Hemorrhage. Obstet Gynecol. 2016 May;127(5):951-6.

[5]. Begley CM, Gyte GML, Devane D, McGuire W, Weeks A. Active versus expectant management for women in the third stage of labour. Cochrane Database of Systematic Reviews 2015, 3.No.: CD007412. DOI: 10.1002/14651858.CD007412.pub4

[6]. Stanton C, et al. Use of active management of the third stage of labor in seven developing countries. Bulletin of the World Health Organization 2009;87:(3):207-215.

[7]. ALSO Asia Pacific. Advanced Life Support in Obstetrics Course Manual. 2nd Edition. Sydney: ALSO Asia Pacific Ltd; 2013.

[8]. WHO. Optimal timing of cord clamping for the prevention of iron deficiency anaemia in infants. Geneva: World Health Organization; 2015.

[9]. Spencer PM. Controlled cord traction in management of the third stage of labor. BMJ 1962;1:1728-32.

[10]. Buchmann E. et al. Guide lines for maternity care in South Africa: manual for clinics, community health centers and district hospitals. 4th. Ed. National Department of Health, Republic of South Africa; 2015

[11]. Kramer MS, Berg C, Abenhaim H, Dahhou M, Rouleau J, Mehrabadi A, Joseph KS. Incidence, risk factors, and temporal trends in severe postpartum hemorrhage. Am J Obstet Gynecol. 2013;209(5):449.e1-7.

[12]. World Health Organization. ACTIVE MANAGEMENT OF THE THIRD STAGE OF LABOUR New WHO Recommendations Help to Focus Implementation. 2012. WHO: Geneva, Switzerland.

[13]. Karim R, Pervaiz F, Muhammad MF. Comparison of active versus expectant management of third stage of labour. J Postgrad Med Inst 2015;29(1): 14-7. 
[14]. Nothnagle M \& Taylor S J. Should Active Management of the Third Stage of Labor Be Routine? Am Fam Physician. 2003 May 15;67(10):2119-2120.

[15]. WHO recommendations for the prevention of postpartum haemorrhage. Geneva: World Health Organization; 2007. Retrieved May14, 2016, from: http://whqlibdoc.who.int/hq/2007/WHO_MPS_07.06_eng.pdf.

[16]. POPPHI. Prevention of Postpartum Hemorrhage: Implementing Active Management of the Third Stage of Labor (AMTSL): A Reference Manual for Health Care Providers. Seattle: PATH; 2007.

[17]. USAID. ANNOTATED BIBLIOGRAPHY Postpartum Hemorrhage: Prevention and Management. Retrieved May14, 2016, from: https://www.k4health.org/sites/default/files/pph_bibliography_v1_2_dec2011_copyright.pdf.

[18]. Antony M. \& Dildy III A. Postpartum hemorrhage: The role of the Maternal-Fetal Medicine specialist in enhancing quality and patient safety. Seminars in perinatology. 2013:37 (4):246-56.

[19]. Salvatore Gizzo, TitoSilvioPatrelli, , StefaniaDi Gangi, Monica Carrozzini, CarloSaccardi, AlessandraZambon, Anna Bertocco, Si mone Fagherazzi, DonatoD’Antona, Giovanni BattistaNardelli. Which Uterotonic Is Better to Prevent the Postpartum Hemorrhage? Latest News in Terms of Clinical Efficacy, Side Effects, and Contraindications: A Systematic Review. Reproductive Sciences. 2013;20 (9):1011-1019

[20]. Gill Gyte. Controlled cord traction. AIMS Journal $2015 ; 27$ (2).

[21]. Dixon L, Tracy S, Guilliland K, Fletcher L, Hendry C, Pairman S, Outcomes of physiological and active third stage labour care amongst women in New Zealand. Midwifery. 2013;29(1):67-74

[22]. Kashanian M, Fekrat M, Masoomi Z, Ansari N. Comparison of active and expectant management on the duration of the third stage of labor and the amount of blood loss during the third and fourth stages of labor: a randomized controlled trial. Midwifery. 2010;26(2):241-245

[23]. Sadler LC, Davison T, McCowan LM. Maternal satisfaction with active management of labor: a randomized controlled trial. Birth. 2001 Dec;28(4):225-35.

[24]. Hodnett ED, Gates S, Hofmeyr GJ, Sakala C. Continuous support for women during childbirth. Cochrane Database Syst Rev 2013; 7:CD003766. 